\title{
Methacholine $\mathrm{PC}_{20}$ In African Americans And Whites With Asthma With Homozygous Genotypes at ADRB2 Codon 16
}

\author{
Kathryn Blake, PharmDa, James D. Cury, $\mathbf{M D}^{\mathrm{b}}$, Jobayer Hossain, $\mathrm{PhD}^{\mathrm{c}}$, Kelan Tantisira, \\ MD $^{\mathrm{d}}$, Jianwei Wang, MD ${ }^{\mathrm{e}}$, Edward Mougey, PhD $^{f}$, and John Lima, PharmDg
}

Kathryn Blake: kblake@nemours.org; James D. Cury: james.cury@jax.ufl.edu; Jobayer Hossain: jhossain@nemours.org; Kelan Tantisira: kelan.tantisira@channing.harvard.edu; Jianwei Wang: Yangyang@bellsouth.net; Edward Mougey: emougey@nemours.org; John Lima: jlima@nemours.org

aCenter for Pharmacogenomics and Translational Research, Nemours Children's Clinic, 807 Children's Way, Jacksonville, FL, 32207 USA

bDepartment of Pulmonary, Critical Care and Sleep Medicine, 655 West 8th Street, University of Florida, Jacksonville, FL 32209 USA

'The Center for Pediatric Research, Alfred I. DuPont Hospital of Children, 1600 Rockland Road, Wilmington, DE; Department of Food and Resource Economics, University of Delaware, Newark, DE 19803 USA

${ }^{d}$ Channing Division of Network Medicine, Brigham and Women's Hospital and Harvard Medical School, 181 Longwood Avenue, Boston, MA 02115 USA

eFormerly at Center for Pharmacogenomics and Translational Research, Nemours Children's Clinic, 807 Children's Way, Jacksonville, FL, 32207 USA

'Center for Pharmacogenomics and Translational Research, Nemours Children's Clinic, 807 Children's Way, Jacksonville, FL, 32207 USA

gCenter for Pharmacogenomics and Translational Research, Nemours Children's Clinic, 807 Children's Way, Jacksonville, FL, 32207 USA

\section{Abstract}

BACKGROUND—African Americans have worse asthma outcomes compared to whites.

Adrenoceptor beta 2, surface gene (ADRB2) Gly16Arg genotypes have been associated with $\beta_{2-}$

(C) 2013 Elsevier Ltd. All rights reserved.

Corresponding Author: Kathryn Blake, PharmD., Nemours Children's Clinic, 807 Children's Way, Jacksonville, FL 32207 USA, Telephone: (904) 697-3806, Fax: (904) 697-3799, kblake@ nemours.org.

All work was performed in the Center for Pharmacogenomics and Translational Research, Nemours Children's Clinic, Jacksonville, FL, USA.

Financial Disclosures and Conflicts of Interest:

Kathryn Blake, PharmD has no conflicts of interest to report.

J Davis Cury, MD has no conflicts of interest to report.

Jobayer Hossain, $\mathrm{PhD}$ has no conflicts of interest to report.

Kelan Tantisira, MD has no conflicts of interest to report.

Jianwei Wang, MD has no conflicts of interest to report.

Ed Mougey, $\mathrm{PhD}$ has no conflicts of interest to report.

John Lima, PharmD has no conflicts of interest to report.

Publisher's Disclaimer: This is a PDF file of an unedited manuscript that has been accepted for publication. As a service to our customers we are providing this early version of the manuscript. The manuscript will undergo copyediting, typesetting, and review of the resulting proof before it is published in its final citable form. Please note that during the production process errors may be discovered which could affect the content, and all legal disclaimers that apply to the journal pertain. 
agonist bronchodilator response, asthma exacerbation rate, response to methacholine, and lung function decline but not specifically in African Americans.

OBJECTIVE-We sought to compare the provocative concentration of methacholine that causes a $20 \%$ fall in $\mathrm{FEV}_{1}\left(\mathrm{PC}_{20}\right)$ in African Americans and whites with asthma who were ADRB2 homozygous at codon16 (Arg16Arg or Gly16Gly).

METHODS-African Americans and whites whose parents and grandparents were of the same race, aged $\geq 10$ years, with baseline $\mathrm{FEV}_{1}$ of $\Varangle 60 \%$ predicted, and no upper or lower respiratory tract infection within the previous 2 weeks meeting genotype criteria were enrolled. $\mathrm{PC}_{20}$ was measured after withholding short-acting and long-acting $\beta_{2}$-agonists for 8 and 12 hours respectively, montelukast for 24 hours, ipratropium bromide and inhaled corticosteroids for 12 hours, and antihistamines for 72 hours.

RESULTS-423 participants were screened and 88 had a positive challenge. Participants were $32 \mathrm{yrs} \pm 19 \mathrm{yrs}$ (mean $\pm \mathrm{SD}$ ), $70 \%$ female, $51 \%$ White (vs. African American), $6 \%$ Hispanic. Similar numbers of participants were using inhaled corticosteroids by race and genotype. There were significant differences in $\log \mathrm{PC}_{20}$ between race/genotype groups $(\mathrm{p}=0.012)$. African American Arg16Arg participants had a lower $\log \mathrm{PC}_{20}$ than White Gly16Gly $(\mathrm{p}=0.009)$ and African American Gly16Gly ( $\mathrm{p}=0.041$ ) participants. Both race and genotype contributed significantly to the model $(\mathrm{p}=0.037$ and $\mathrm{p}=0.014$, respectively) but there was no interaction between race and genotype on $\log \mathrm{PC}_{20}$.

CONCLUSIONS AND CLINICAL RELEVANCE-Airway hyperresponsiveness is influenced by race and the $A D R B 2$ codon 16 polymorphism. African Americans with the Arg16Arg genotype have increased airway reactivity and may be at risk for worse asthma outcomes. Inclusion of genetic information as an additional clinical tool may aid in the personalization of asthma management decisions.

[ClinicalTrials.gov Identifier: NCT00708227].

\section{Keywords}

African American; White; methacholine; asthma; $A D R B 2$; genotype

\section{INTRODUCTION}

Asthma affects nearly 25 million persons in the United States (8.2\%) and is more prevalent in African Americans than whites (11.1\% v. 7.8\%) [1] and even greater racial prevalence differences exist in children (16\% and 8.2\%, respectively) [2]. Compared to whites, African Americans tend to have more severe and frequent exacerbations, more hospitalizations, a greater risk of death, lower quality of life, more frequent short-acting $\beta_{2}$-agonist use, less inhaled corticosteroid (ICS) use, a poorer response to short-and long-acting inhaled $\beta_{2^{-}}$ agonists, and are more likely to be steroid insensitive [1,3-7]. In addition, African Americans are more likely than whites to have a greater risk of asthma related life threatening events or death when using long-acting $\beta_{2}$-agonists which may reflect underuse of inhaled corticosteroids [7]. The reason for worse asthma outcomes in African Americans is not readily clear but may be related to yet unspecified composites of genetic and environmental factors.

Airway hyperresponsiveness is present in nearly all persons with active asthma and can be detected by direct (methacholine, histamine, leukotriene, prostaglandin) or indirect (exercise, hypertonic saline, adenosine monophosphate, mannitol, eucapnic voluntary hyperpnea) bronchial challenge $[8,9]$. Although, sensitivity measured by the challenge may be affected by procedure methodology; for instance, deep inspiration or choice of agent may 
influence response [10-12]. Few studies have included an analysis of differences in airway hyperreactivity (assessed by methacholine bronchial challenge) between African Americans and whites with asthma [13-17]. In several studies, no difference in methacholine sensitivity was noted between African American and whites [13-15] though in two studies African Americans had greater sensitivity to methacholine compared to whites $[16,17]$.

Polymorphisms in the gene encoding the $\beta_{2}$-adrenergic receptor (ADRB2) have been associated with asthma phenotypes $[18,19]$. Two nonsynonomous coding polymorphisms have been comprehensively studied both in vitro and in clinical trials: glycine (Gly) 16 to arginine (Arg) and glutamine (Gln) 27 to glutamate (Glu) because both result in functional changes of the receptor protein observed in vitro and both occur at high frequency (>10\%) in patients with asthma including whites and African Americans. Associations between methacholine sensitivity and the Gly16Arg polymorphism have been mixed in both asthma and the general population [18, 20-24]. Similarly, associations of the Gly16Arg polymorphism with other asthma phenotypes such as lung function, asthma control, and persistence of asthma to adulthood, and nocturnal symptoms have been mixed [18, 19, 22, $23,25,26]$. However, most studies were conducted in whites or Asians, or surprisingly did not report race at all. Thus, there are no data specifically examining asthma outcomes by $A D R B 2$ genotype in a racially homogenous group of whites versus African Americans.

We measured airway hyperresponsiveness by methacholine bronchial challenge in African Americans and whites who were homozygous at the $A D R B 2$ Gly16Arg codon. We hypothesized that race and $A D R B 2$ would predict response to the provocative concentration of methacholine that causes a $20 \%$ fall in $\mathrm{FEV}_{1}\left(\mathrm{PC}_{20}\right)$.

\section{MATERIALS AND METHODS}

\subsection{Participants}

Participants were recruited for the main clinical trial, "Pharmacogenetics of $\beta_{2}$-Agonists in Asthma" (ClinicalTrials.gov Identifier: NCT00708227) from Nemours Children's Clinic, Jacksonville FL. Male and female participants were eligible if they had physician diagnosed asthma for at least 3 months; were aged 10 years or older; race was African American or white with consistent race back to the grandparent generation by participant self-report; $A D R B 2$ Gly 16 Arg genotype was Arg 16 Arg or Gly $16 \mathrm{Gly}$; FEV 1 was $\geq 60 \%$ of predicted normal values for age, height, and sex; there was no history of life-threatening asthma that required intubation associated with hypercapnia, respiratory arrest, or hypoxic seizures; there was no hospitalization for asthma within the previous 3 months; there was no respiratory tract infection (sinus, middle ear, oropharyngeal, upper or lower respiratory tract infection ) nor episodic increase in asthma symptoms not completely resolved for at least 2 weeks before the visit; there was no oral corticosteroid use for at least 2 weeks before the visit; and females were not pregnant or lactating. There was no requirement for previous asthma therapy including baseline inhaled corticosteroid treatment. All persons with a smoking history (past or present) could not have physician diagnosed COPD nor a FEV / $_{1}$ FVC ratio $<0.70$ if the participant was $>40$ years old. Participants who were current smokers under 40 years old were considered "smoking asthmatics" regardless of smoking history. Institutional review board approval was obtained from Nemours Florida Institutional Review Board. Prior to the study, a signed and dated written informed consent from adults aged 18 years and older, and parental permission from a child's parent or legal guardian, and assent from children aged 7 to 17 years old, was obtained.

Data were collected on date of asthma onset, current medication use, current symptoms based upon Asthma Control Questionnaire (ACQ) results [permission granted from Elizabeth Juniper] [27, 28], clinical history of symptoms to aeroallergens, and smoking 
history. The ACQ is a self-administered instrument that contains 6 questions scored on a 7point scale ( 0 , good control to 6 , poor control) that asks patients to recall symptoms and short-acting $\beta_{2}$-agonist use during the previous week and has been validated in adults and children aged 6 years and older $[27,28]$. A seventh item in the ACQ is a score based on pulmonary function results. The overall ACQ score is mean from the 7 items and a score of 0.75 or less indicates well-controlled asthma and a score 1.5 or greater indicates inadequately controlled asthma [28].

\subsection{Study Design and Drug Administration}

The data were collected from a single study visit after all inclusion criteria were met. Women of child bearing potential had a urine pregnancy test performed on the day of the visit. Methacholine (Provocholine ${ }^{\circledR}$ Methapharm Inc. Brantford, Ontario, Canada) kits from Methapharm Inc. contained methacholine chloride $100 \mathrm{mg}$ powder and diluent $[0.9 \%$ sodium chloride injection containing $0.4 \%$ phenol $(\mathrm{pH} 7.0)]$. Dilutions were prepared and stored prior to use according the manufacturer labeling.

Prior to the methacholine challenge, participants had to discontinue short- and long-acting $\beta_{2}$-agonists for 8 and 12 hours, respectively; inhaled corticosteroids for 12 hours; ipratropium bromide for 12 hours; montelukast for 24 hours; antihistamines for 72 hours; and caffeine containing products for 8 hours. Long-acting $\beta_{2}$-agonists were only held 12hours for consistency of washout requirements and study design in the main trial, "Pharmacogenetics of $\beta_{2}$-Agonists in Asthma". Participants were told not to exercise for 6 hours or to expose themselves to environments known to precipitate asthma symptoms for 48 hours before the challenge. No participant was studied during a season in which they historically reported sensitivity to prevalent aeroallergens. All challenges were performed by the principal investigator or two highly trained asthma clinical research nurses.

Bronchoconstriction following the challenge was reversed with nebulized albuterol.

Spirometry was performed according to ATS guidelines [29]. At baseline at least three acceptable forced vital capacity maneuvers, with the two highest forced expiratory volume in the $1^{\text {st }}$ second $\left(\mathrm{FEV}_{1}(\mathrm{~L})\right)$ values within $5 \%$ of each other, were obtained and the highest value for $\mathrm{FEV}_{1}$ was recorded [29]. The participant was seated and wearing a nose clip during all spirometry efforts. Hankinson (NHANES III) predicted values were used to determine the percent predicted $\mathrm{FEV}_{1}$ [30]; values for African Americans were adjusted by $12 \%$.

The methacholine challenge was performed according to the ATS protocol using 10 doubling concentrations of methacholine, diluent followed by $0.03,0.06,0.125,0.25,0.50$, $1,2,4,8,16 \mathrm{mg} / \mathrm{ml}$, delivered by a DeVilbiss 646 characterized nebulizer connected to a KoKo Dosimeter [31]. Only two DeVilbiss 646 characterized nebulizers were used during the study and had manufacturer tested outputs of $1.012 \mathrm{~mL} / \mathrm{min}$ and $1.014 \mathrm{~mL} / \mathrm{min}$, respectively, (tested by Ferraris Respiratory, Louisville, KY). The output from the nebulizers was checked after each 20 uses [31]. The nebulizers were cleaned after each use in hot soapy water, disinfected with Cidex OPA (Johnson \& Johnson, Irvine, CA), and allowed to air dry according to manufacturer instructions [32]. The air pressure source to the input valve of the dosimeter was set to $30 \mathrm{psi}$. The dosimeter was set to deliver each dose of methacholine with a 0.4 second start delay and 0.6 second dose duration. Five inspiratory breaths, from functional residual capacity to total lung capacity, of increasing doses of methacholine were sequentially inhaled. The first inhalation of each incremental dose of methacholine was begun 5 minutes after the first inhalation of the previous dose. A single $\mathrm{FEV}_{1}$ of acceptable quality was recorded at 30 seconds and again at 90 seconds after the fifth inhalation of each dose from the nebulizer. The highest $\mathrm{FEV}_{1}$ after each dose whether at 30 or 90 seconds was selected for calculation of $\mathrm{PC}_{20}$. Increasing doses of methacholine 
were administered until the highest post-dose $\mathrm{FEV}_{1}$ had decreased by $20 \%$ from the highest post-diluent $\mathrm{FEV}_{1}$ or until the highest dose of methacholine $(16 \mathrm{mg} / \mathrm{mL})$ was administered. The methacholine $\mathrm{PC}_{20}$ was determined by linear interpolation of the highest $\mathrm{FEV}_{1}$ from the last 2 doses of methacholine plotted against the log-dose of methacholine [33].

\subsection{DNA Collection and Genotyping}

Genomic DNA was collected via saliva or blood donation. Saliva was collected using the Oragene•DNA DNA Self-Collection Kit (OG-100 Vial Format) (http:// www.dnagenotek.com). Saliva samples were stored at $15-30{ }^{\circ} \mathrm{C}$ until analys is. Saliva samples were prepared for genotyping according to the manufacturer instructions (http:// www.dnagenotek.com/US/support/protocols.html). The ADRB2 Gly16Arg genotypes were determined by analyzing the melting curves of fluorescent-labeled oligo probes bound to PCR-generated targets from individual DNA samples on a LightTyper instrument (Roche Applied Science, Indianapolis, IN, USA) as previously described [34].

Blood from a small number of participants had been previously genotyped via a Sequenom matrix-assisted laser desorption/ionization time-of-flight (MALDI-TOF) mass array spectrometer (Sequenom, San Diego, CA), using a semi automated primer design program (Spectro Designer; Sequenom) [35].

\subsection{Statistical Analysis}

Participants were assigned to one of four groups based upon race and ADRB2 Gly16Arg genotype: white Arg16Arg; white Gly16Gly; African American Arg16Arg; African American Gly16gly. Categorical variables were summarized by frequencies and percentages, while quantitative variables were summarized using mean and standard deviation (SD). The distribution of baseline characteristics were compared between groups by Chi square test for nominal data and one-way analysis of variance (ANOVA) for continuous data. Model assumptions were checked before the analysis and an appropriate measure was taken in case of violation. A factorial ANOVA was performed to analyze the $\log _{10}$ transformed $\mathrm{PC}_{20}$ [36]. Race, genotype, and interaction of race and genotype were used in the initial model. Later, the model was adjusted for influential covariates such as age, sex, baseline $\mathrm{FEV}_{1}$ percent predicted, years with asthma, Asthma Control Questionnaire score [28], clinical history of symptoms to aeroallergens, baseline inhaled corticosteroid (ICS) use, and history of having ever smoked. Post hoc analysis was performed using Tukey HSD. All tests were two-tailed at the level of significance of 0.05. Data were analyzed using statistical software SPSS Version 19.0.0, SPSS Inc., Chicago, IL, USA.

\section{RESULTS}

\subsection{Participant Characteristics}

Saliva or blood was analyzed from 423 individuals with asthma to determine $A D R B 2$ Gly16Arg genotype. Genotype results were reviewed from an additional 145 previous study participants who had signed consent documents allowing for storage and future use of donated DNA. Inclusion criteria were met by 132 available participants who underwent a methacholine challenge. Of the 132 participants who met the inclusion criteria, $88 \mathrm{had}$ a positive methacholine challenge test defined as $\mathrm{PC}_{20}<16 \mathrm{mg} / \mathrm{mL}$. Characteristics of the 88 participants who had a positive MCT are presented in Table 1. Age was $14 \mathrm{yrs} \pm 2 \mathrm{yrs}$ in those $<18$ years old $(n=30)$ and 41 yrs \pm 17 yrs in those $\geq 18$ years old $(n=58)($ mean \pm SD). There were no significant differences in participants $<18$ years old and those $\geq 18$ years old for race, genotype at Gly16Arg, ICS use at baseline, or clinical history of symptoms to aeroallergens. There were similar numbers of males vs. female in those $<18$ years old but more female participants in those $\geq 18$ years old $(\mathrm{p}=0.02)$. Mean $\pm \mathrm{SD}$ percent predicted 
$\mathrm{FEV}_{1}$ at baseline was higher in those $<18$ years old vs. $\geq 18$ years old $(97 \% \pm 15 \%$ vs. $82 \%$ $\pm 14 \%, \mathrm{p}<0.0001$ ), respectively. Because the number of whites and African Americans were similar within genotype groups, the minor allele frequencies were also similar, thus precluding the risk of confounding by population stratification.

There were no differences in age, sex, ethnicity (Hispanic/not Hispanic), race, ADRB2 Gly16Arg genotype, having ever smoked, any ICS use at the time of the visit, clinical history of symptoms to aeroallergens, or mean ACQ score between participants who failed versus those with a positive MCT. Asthma duration was less (13 years vs. 20 years, $\mathrm{p}=0.011)$ and baseline $\mathrm{FEV}_{1}$ percent predicted tended to be higher $(93 \%$ vs. $87 \%, \mathrm{p}=0.058)$ in those who failed MCT compared with those who had a positive MCT, respectively.

There were statistically significant differences in mean $\log \mathrm{PC}_{20}$ between race/genotype groups ( $\mathrm{p}=0.012$ ) (Figure 1). Geometric mean $\mathrm{PC}_{20}(\mathrm{mg} / \mathrm{mL}$ ) values and $95 \%$ confidence intervals for whites with the Arg16Arg and Gly16Gly genotypes were $1.27(0.64,2.50)$ and $1.76(1.02,3.054)$, respectively, and for African Americans, $0.48(0.26,0.86)$ and $1.42(0.84$, $2.40)$, respectively. Multiple comparison analysis demonstrated significant differences in log $\mathrm{PC}_{20}$ between African American Arg16Arg vs. both White Gly16Gly ( $\left.\mathrm{p}=0.009\right)$ and African American Gly16Gly ( $\mathrm{p}=0.041$ ). Unadjusted factorial ANOVA of $\log \mathrm{PC}_{20}$ by race and genotype showed significant differences by genotype $(\mathrm{p}=0.014)$ and race $(\mathrm{p}=0.037)$ but there was no interaction between race and genotype on $\log \mathrm{PC}_{20}$. Inclusion of age, duration of asthma, and baseline $\mathrm{FEV}_{1} \%$ predicted as covariates did not change these findings. Inclusion of Asthma Control Questionnaire [27] score into the model resulted in race no longer being significant. Inclusion of clinical history of symptoms to aeroallergens resulted in neither race nor genotype being significant; however, $88 \%$ of participants had a history of clinical sensitivity to aeroallergens. Inclusion of sex resulted in an interaction between race, genotype, and sex being significant ( $\mathrm{p}=0.031$ ) (Table 2). Inclusion of having ever smoked resulted in statistical significance for smoking $(\mathrm{p}=0.006)$, interaction between race and genotype ( $\mathrm{p}=0.038)$, and interaction between smoking, race, and genotype $(\mathrm{p}=0.018)$ (Table 3 ). An interaction was also present between ICS use and genotype ( $\mathrm{p}=0.034)$ such that in participants on ICS, those with the Arg 16Arg genotype had a lower $\log \mathrm{PC}_{20}$ than those with the Gly16Gly genotype (Table 4). Within genotype, there were no differences in log $\mathrm{PC}_{20}$ between users and nonusers of ICS. In addition, there was no interaction between ICS use and race $(\mathrm{p}=0.30)$ nor ICS use, race, and genotype combined in the model $(\mathrm{p}=0.298)$.

\section{DISCUSSION}

Compared to whites, African Americans are frequently described as having greater morbidity and mortality rates as well as a poorer response to asthma medications and quite concerning, an increased risk of life-threatening outcomes or death when on long-acting $\beta_{2^{-}}$ agonists [1, 3-7]. We identified a sub-group of African Americans with the ADRB2 Arg16Arg genotype who has significantly lower methacholine $\mathrm{PC}_{20}$ compared to either whites or African Americans with the Gly16Gly genotype. To our knowledge, this study is the first to examine methacholine $\mathrm{PC}_{20}$ as a function of both race and $A D R B 2$ genotype.

The observed differences in the mean $\log \mathrm{PC}_{20}$ between race/genotype stratified groups cannot be explained by population stratification as minor allele frequencies were virtually the same between whites and African Americans nor by differences in mean group covariate characteristics. Participants were enrolled in the study only if their asthma was stable, defined by no asthma exacerbation requiring hospitalization in the past 3 months and no asthma symptoms resulting from a respiratory tract infection or asthma exacerbation, no episodic increase in symptoms, nor any oral corticosteroid use within 2 weeks prior to the visit. Nor were any participants studied in the months they historically reported symptoms to 
aeroallergens. No differences were found in the percent of females, age, asthma duration, \% predicted baseline $\mathrm{FEV}_{1}$, ICS use, history of clinical symptoms to aeroallergen, \% who had never smoked, or asthma severity assessed by ACQ between the race/genotype groups to explain these findings. While percent predicted $\mathrm{FEV}_{1}$ was higher in those less than 18 years old, the distribution of patients by $<18$ years old or $\geq 18$ years old was not different by race or Gly16Arg genotype.

We chose to use methacholine because it is FDA approved, safety data are available in children [37], and numerous published studies are available which aided in the assessment of variability and calculation of sample size estimates during the main trial design. In addition, bronchial challenge with methacholine is considered a direct test of airway hyperresponsiveness as its action is specific to the airway smooth muscle receptor compared with indirect tests using exercise, cold dry air, mannitol, or adenosine that appear to act through the release of inflammatory mediators within the airway [12].

Inclusion of sex, having ever smoked, and ICS use into our model resulted in several statistically significant interactions with race or genotype, or both race and genotype. African Americans with the Arg16Arg genotype who were female or who were smokers had the lowest $\log \mathrm{PC}_{20}$. Previous studies have found that post-pubertal female children with asthma have greater airway hyperresponsiveness compared to males $[38,39]$ though no differences between sexes were found in a recent study in mostly adults [17]. Cigarette smoke exposure can also increase airway hyperresponsiveness in patients with asthma but there is large heterogeneity in effect [40,41]. Thus we may have identified a subgroup of patients with asthma by race, $A D R B 2$ genotype, sex, and smoking history that are at increased risk for having airway hyperresponsiveness.

Approximately $50 \%$ of participants in each race/genotype group in the present study were using inhaled corticosteroids ( $89 \%$ as combination of inhaled corticosteroid plus a longacting $\beta_{-2}$-agonist). We found an interaction between any form of ICS use and genotype but there was no influence of race. Unlike Rebordosa et al who found that in patients not on ICS, those with the Arg16Arg genotype had increased airway hyperresponsiveness compared to Gly16Gly carriers [22], we found no difference between genotypes in patients not on ICS. However, we did find that in participants on ICS those with the Arg16Arg genotype had a significantly lower $\mathrm{PC}_{20}$ than those with the Gly16Gly genotype.

Our study has several limitations. The effects observed were based upon $A D R B 2$ genotype at a single locus. Haplotypes may be more informative in performing association studies than single nucleotide polymorphisms due to capturing effects of alleles which are in linkage disequilibrium with other polymorphisms [42, 43]. For our challenge methodology, we elected to use the ATS dosimeter method with a slow 5-second inhalation to total lung capacity. Several studies have now confirmed that deep inspiration during methacholine challenge testing results in a higher $\mathrm{PC}_{20}$ compared with tidal breathing [10,11]. Having our participants inhale deeply could help explain the large percent (33\%) of individuals who failed to achieve a $\mathrm{PC}_{20}<16 \mathrm{mg} / \mathrm{mL}$. The latter may also be explained by the 12-hour washout for long-acting $\beta_{2}$-agonists which may have allowed residual bronchodilation to blunt or inhibit the response to methacholine. Racial ancestry was determined by self-report rather than genotyping ancestral markers to determine African American vs. European Caucasian heritage. However, all participants were recruited from a single center in the southeastern United States where large populations of African American reside and those of Hispanic ethnicity comprise less than $4 \%$ of the population. In addition, only participants who could state that parents and grandparents were of the same race as the participant were enrolled and self-reported race has been shown to distinguish between whites and African Americans in urban populations [44]. ICS use was by self-report and we did not examine 
prescription fill records to determine if ICS had been used consistently in the months before the visit. Patient adherence with ICS treatment plans is frequently reported to be poor [45, 46].

\section{CONCLUSIONS}

We found that African Americans with the ADRB2 Arg16Arg genotype, particularly females who had ever smoked, have significantly increased airway hyperresponsiveness (lower $\mathrm{PC}_{20}$ ) compared to either whites or African Americans with the Gly16Gly genotype. Our findings are relevant for clinicians who manage asthma in African Americans. Because increased airway hyperresponsiveness is correlated with asthma severity, this group of African Americans may require more aggressive treatment regimens and monitoring to reduce impairment and future risks. Inclusion of genetic information as an additional tool to personalize asthma treatment choices and management strategies likely will become increasingly common as the costs for genome sequencing continue to decrease.

\section{Acknowledgments}

Supported by NIH grant 5K23HL081245 (to K. Blake), R01 NR013391 (to K. Tantisira)

The authors thank Stacey Gray for recruitment efforts and Heather Cross for data entry and cross checking.

\section{Abbreviations}

ADRB2 adrenergic, beta-2-, receptor surface gene

Arg arginine

$\mathbf{F E V}_{1} \quad$ volume of air expired in the first second during maximal expiratory effort

Gln glutamine

Glu glutamate

Gly glycine

$\mathbf{P C}_{20}$ provocative concentration of methacholine that causes a $20 \%$ fall in $\mathrm{FEV}_{1}$

\section{References}

1. Akinbami LJ, Moorman JE, Liu X. Asthma prevalence, health care use, and mortality: United States, 2005-2009. Natl Health Stat Report. 2011:1-14. [PubMed: 21355352]

2. EPA. President's Task Force on Environmental Health Risks and Safety Risks to Children: Coordinated Federal Action Plan to Reduce Racial and Ethnic Asthma Disparities. Environmental Protection Agency; 2012. wwwepagov/childrenstaskforce

3. Blake K, Madabushi R, Derendorf H, Lima J. Population pharmacodynamic model of bronchodilator response to inhaled albuterol in children and adults with asthma. Chest. 2008; 134:981-9. [PubMed: 18583517]

4. Crocker D, Brown C, Moolenaar R, Moorman J, Bailey C, Mannino D, et al. Racial and ethnic disparities in asthma medication usage and health-care utilization: data from the National Asthma Survey. Chest. 2009; 136:1063-71. [PubMed: 19567492]

5. Chan MT, Leung DY, Szefler SJ, Spahn JD. Difficult-to-control asthma: clinical characteristics of steroid-insensitive asthma. J Allergy Clin Immunol. 1998; 101:594-601. [PubMed: 9600494]

6. Haselkorn T, Lee JH, Mink DR, Weiss ST. Racial disparities in asthma-related health outcomes in severe or difficult-to-treat asthma. Ann Allergy Asthma Immunol. 2008; 101:256-63. [PubMed: 18814448] 
7. Levenson, M. Long-Acting Beta-Agonists and Serious Asthma-Related Events Meta-Analysis. Food and Drug Administration, Joint Meeting of the Pulmonary-Allergy Drugs Advisory Committee, Drug Safety and Risk Management Advisory Committee and Pediatric Advisory Committee; Joint Meeting of the Pulmonary-Allergy Drugs Advisory Committee, Drug Safety and Risk Management Advisory Committee and Pediatric Advisory Committee; December 10, 2008; 2008.

8. Moore WC, Meyers DA, Wenzel SE, Teague WG, Li H, Li X, et al. Identification of asthma phenotypes using cluster analysis in the Severe Asthma Research Program. Am J Respir Crit Care Med. 2010; 181:315-23. [PubMed: 19892860]

9. Cockcroft DW. Direct challenge tests: Airway hyperresponsiveness in asthma: its measurement and clinical significance. Chest. 2010; 138:18S-24S. [PubMed: 20668014]

10. Allen ND, Davis BE, Hurst TS, Cockcroft DW. Difference between dosimeter and tidal breathing methacholine challenge: contributions of dose and deep inspiration bronchoprotection. Chest. 2005; 128:4018-23. [PubMed: 16354875]

11. Cockcroft DW, Davis BE. The bronchoprotective effect of inhaling methacholine by using total lung capacity inspirations has a marked influence on the interpretation of the test result. J Allergy Clin Immunol. 2006; 117:1244-8. [PubMed: 16750982]

12. O'Byrne PM, Gauvreau GM, Brannan JD. Provoked models of asthma: what have we learnt? Clin Exp Allergy. 2009; 39:181-92. [PubMed: 19187330]

13. Hardie G, Liu R, Darden J, Gold WM. Ethnic differences in methacholine responsiveness and word descriptors in African Americans, Hispanic-Mexican Americans, Asian-Pacific Islanders, and Whites with mild asthma. J Asthma. 2010; 47:388-96. [PubMed: 20528591]

14. Hardie GE, Brown JK, Gold WM. Bronchial hyperresponsiveness, word descriptors, and ethnicity: women with mild asthma. J Asthma. 2012; 49:36-44. [PubMed: 22176690]

15. Wechsler ME, Castro M, Lehman E, Chinchilli VM, Sutherland ER, Denlinger L, et al. Impact of race on asthma treatment failures in the asthma clinical research network. Am J Respir Crit Care Med. 2011; 184:1247-53. [PubMed: 21885625]

16. Joseph CL, Ownby DR, Peterson EL, Johnson CC. Racial differences in physiologic parameters related to asthma among middle-class children. Chest. 2000; 117:1336-44. [PubMed: 10807820]

17. Sumino K, Sugar EA, Irvin CG, Kaminsky DA, Shade D, Wei CY, et al. Methacholine challenge test: Diagnostic characteristics in asthmatic patients receiving controller medications. J Allergy Clin Immunol. 2012; 130:69-75. e6. [PubMed: 22465214]

18. Contopoulos-Ioannidis DG, Manoli EN, Ioannidis JP. Meta-analysis of the association of beta2adrenergic receptor polymorphisms with asthma phenotypes. J Allergy Clin Immunol. 2005; 115:963-72. [PubMed: 15867853]

19. Hall IP, Blakey JD, Al Balushi KA, Wheatley A, Sayers I, Pembrey ME, et al. Beta2-adrenoceptor polymorphisms and asthma from childhood to middle age in the British 1958 birth cohort: a genetic association study. Lancet. 2006; 368:771-9. [PubMed: 16935688]

20. Wilson AM, Gray RD, Hall IP, Lipworth BJ. The effect of beta2-adrenoceptor haplotypes on bronchial hyper-responsiveness in patients with asthma. Allergy. 2006; 61:254-9. [PubMed: 16409205]

21. van Veen A, Wierenga EA, Westland R, Weller FR, Hart GA, Jansen HM, et al. Limited beta2adrenoceptor haplotypes display different agonist mediated airway responses in asthmatics. Respir Res. 2006; 7:19. [PubMed: 16448568]

22. Rebordosa C, Kogevinas M, Guerra S, Castro-Giner F, Jarvis D, Cazzoletti L, et al. ADRB2 Gly16Arg polymorphism, asthma control and lung function decline. Eur Respir J. 2011; 38:102935. [PubMed: 21436355]

23. Zhang G, Hayden CM, Khoo SK, Laing IA, Turner S, Landau L, et al. Association of haplotypes of beta2-adrenoceptor polymorphisms with lung function and airway responsiveness in a pediatric cohort. Pediatr Pulmonol. 2006; 41:1233-41. [PubMed: 17068824]

24. Joos L, Weir TD, Connett JE, Anthonisen NR, Woods R, Pare PD, et al. Polymorphisms in the beta2 adrenergic receptor and bronchodilator response, bronchial hyperresponsiveness, and rate of decline in lung function in smokers. Thorax. 2003; 58:703-7. [PubMed: 12885990] 
25. Zhang G, Hayden CM, Khoo SK, Candelaria P, Laing IA, Turner S, et al. Beta2-Adrenoceptor polymorphisms and asthma phenotypes: interactions with passive smoking. Eur Respir J. 2007; 30:48-55. [PubMed: 17428813]

26. Thakkinstian A, McEvoy M, Minelli C, Gibson P, Hancox B, Duffy D, et al. Systematic review and meta-analysis of the association between \{beta\}2-adrenoceptor polymorphisms and asthma: a HuGE review. Am J Epidemiol. 2005; 162:201-11. [PubMed: 15987731]

27. Juniper EF, O’Byrne PM, Guyatt GH, Ferrie PJ, King DR. Development and validation of a questionnaire to measure asthma control. Eur Respir J. 1999; 14:902-7. [PubMed: 10573240]

28. Juniper EF, Bousquet J, Abetz L, Bateman ED. Identifying 'well-controlled' and 'not wellcontrolled' asthma using the Asthma Control Questionnaire. Respir Med. 2006; 100:616-21. [PubMed: 16226443]

29. Miller MR, Hankinson J, Brusasco V, Burgos F, Casaburi R, Coates A, et al. Standardisation of spirometry. Eur Respir J. 2005; 26:319-38. [PubMed: 16055882]

30. Hankinson JL, Odencrantz JR, Fedan KB. Spirometric reference values from a sample of the general U.S. population. Am J Respir Crit Care Med. 1999; 159:179-87. [PubMed: 9872837]

31. Crapo RO, Casaburi R, Coates AL, Enright PL, Hankinson JL, Irvin CG, et al. Guidelines for methacholine and exercise challenge testing-1999. This official statement of the American Thoracic Society was adopted by the ATS Board of Directors, July 1999. Am J Respir Crit Care Med. 2000; 161:309-29. [PubMed: 10619836]

32. Personal communication with Dan Graff. nSpire Health, Inc; Longmont, CO: Sep 27. 2010

33. Cockcroft DW, Murdock KY, Mink JT. Determination of histamine PC20. Comparison of linear and logarithmic interpolation. Chest. 1983; 84:505-6. [PubMed: 6617292]

34. Steward DL, Grisel J, Meinzen-Derr J. Steroids for improving recovery following tonsillectomy in children. Cochrane Database Syst Rev. 2011:CD003997. [PubMed: 21833946]

35. Bray MS, Boerwinkle E, Doris PA. High-throughput multiplex SNP genotyping with MALDI-TOF mass spectrometry: practice, problems and promise. Hum Mutat. 2001; 17:296-304. [PubMed: 11295828]

36. Peat JK, Unger WR, Combe D. Measuring changes in logarithmic data, with special reference to bronchial responsiveness. J Clin Epidemiol. 1994; 47:1099-108. [PubMed: 7722543]

37. Covar RA, Colvin R, Shapiro G, Strunk R. Safety of methacholine challenges in a multicenter pediatric asthma study. J Allergy Clin Immunol. 2006; 117:709-11. [PubMed: 16522478]

38. Bisgaard H, Pedersen S, Anhoj J, Agertoft L, Hedlin G, Gulsvik A, et al. Determinants of lung function and airway hyperresponsiveness in asthmatic children. Respir Med. 2007; 101:1477-82. [PubMed: 17336509]

39. Tantisira KG, Colvin R, Tonascia J, Strunk RC, Weiss ST, Fuhlbrigge AL. Airway responsiveness in mild to moderate childhood asthma: sex influences on the natural history. Am J Respir Crit Care Med. 2008; 178:325-31. [PubMed: 18420965]

40. Nowak D, Jorres R, Schmidt A, Magnussen H. Effect of 3 hours' passive smoke exposure in the evening on airway tone and responsiveness until next morning. Int Arch Occup Environ Health. 1997; 69:125-33. [PubMed: 9001919]

41. Meghji Z, Dua B, Watson RM, Gauvreau GM, O’Byrne PM. Allergen inhalation challenge in smoking compared with non-smoking asthmatic subjects. Clin Exp Allergy. 2011; 41:1084-90. [PubMed: 21631611]

42. Drysdale CM, McGraw DW, Stack CB, Stephens JC, Judson RS, Nandabalan K, et al. Complex promoter and coding region beta 2-adrenergic receptor haplotypes alter receptor expression and predict in vivo responsiveness. Proc Natl Acad Sci USA. 2000; 97:10483-8. [PubMed: 10984540]

43. Litonjua AA, Silverman EK, Tantisira KG, Sparrow D, Sylvia JS, Weiss ST. Beta 2-adrenergic receptor polymorphisms and haplotypes are associated with airways hyperresponsiveness among nonsmoking men. Chest. 2004; 126:66-74. [PubMed: 15249444]

44. Sinha M, Larkin EK, Elston RC, Redline S. Self-reported race and genetic admixture. N Engl J Med. 2006; 354:421-2. [PubMed: 16436780]

45. Krishnan JA, Bender BG, Wamboldt FS, Szefler SJ, Adkinson NF Jr, Zeiger RS, et al. Adherence to inhaled corticosteroids: an ancillary study of the Childhood Asthma Management Program clinical trial. J Allergy Clin Immunol. 2012; 129:112-8. [PubMed: 22104610] 
46. Williams LK, Peterson EL, Wells K, Campbell J, Wang M, Chowdhry VK, et al. A clusterrandomized trial to provide clinicians inhaled corticosteroid adherence information for their patients with asthma. J Allergy Clin Immunol. 2010; 126:225-31. 31, e1-4. [PubMed: 20569973]

47. National Asthma Education and Prevention Program. Expert panel report 3: guidelines for the diagnosis and management of asthma. Bethesda, MD: U.S. Department of Health and Human Services, Public Health Service, National Institutes of Health, National Heart, Lung, and Blood Institute; 2007. [publication no. 08-4051] 


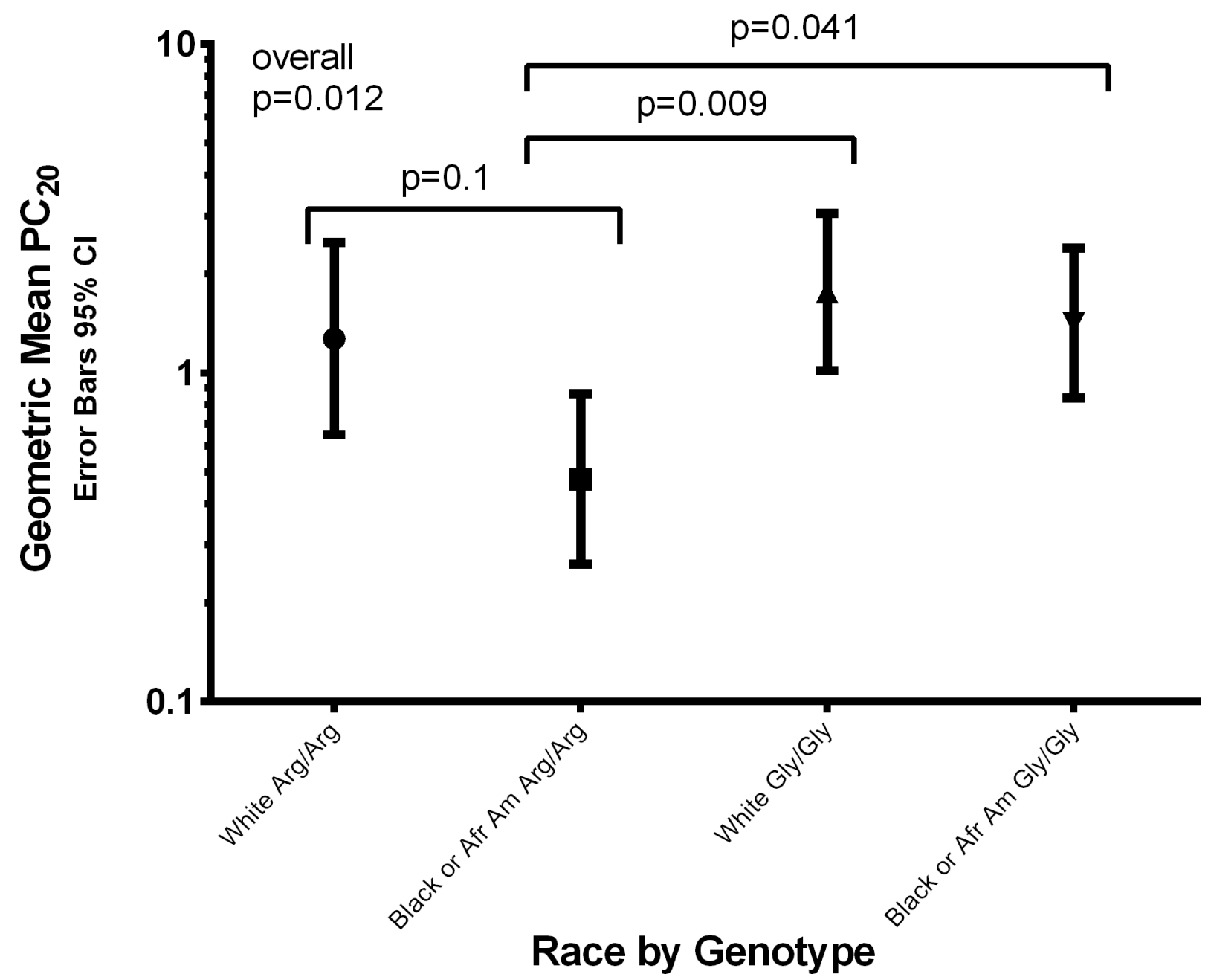

Figure 1.

Geometric mean $\mathrm{PC}_{20}$ with $95 \%$ confidence interval error bars for the 4 race by genotype groups.

There were significant differences between the mean $\log \mathrm{PC}_{20}$ values of the 4 groups $(\mathrm{p}=0.012)$. African Americans who carried the Arg16Arg genotype had significantly lower mean $\log \mathrm{PC}_{20}$ compared to whites with the Gly16Gly genotype $(\mathrm{p}=0.009)$ and African Americans with the Gly16Gly genotype $(\mathrm{p}=0.041)$. There was no significant difference between whites and African Americans with the Arg16Arg genotype ( $\mathrm{p}=0.1)$.

Afr Am = African American 


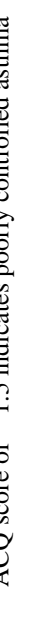




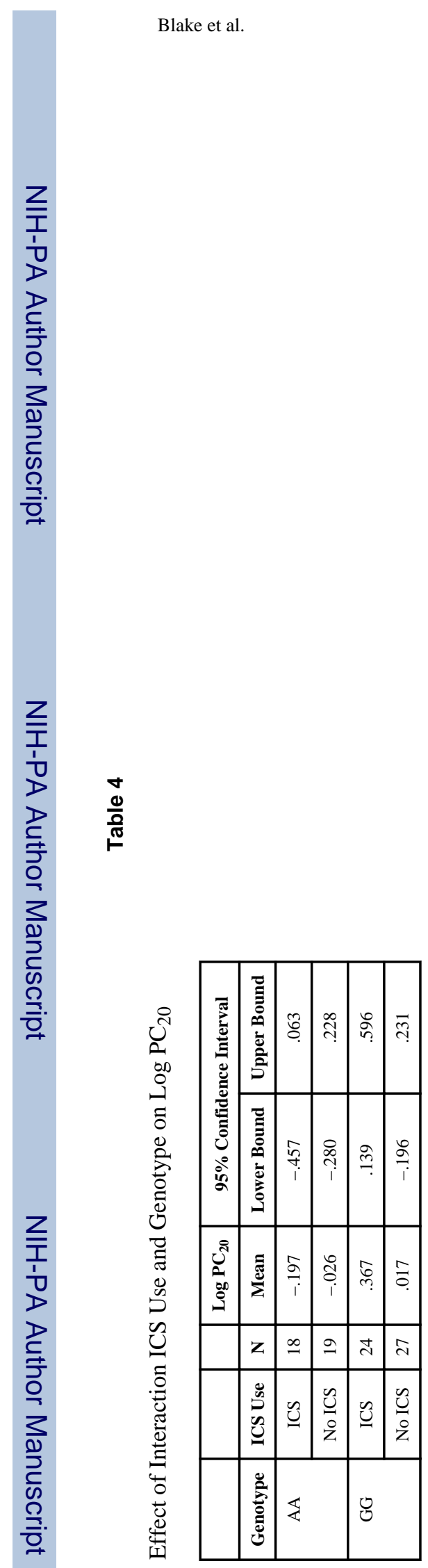

Page 17

Pulm Pharmacol Ther. Author manuscript; available in PMC 2014 June 01. 